NBER WORKING PAPER SERIES

\author{
THE VALUATION OF CASH \\ FLOW FORECASTS: AN \\ EMPIRICAL ANALYSIS
}

Steven N. Kaplan

Richard S. Ruback

Working Paper No. 4724

\author{
NATIONAL BUREAU OF ECONOMIC RESEARCH \\ 1050 Massachusetts Avenue \\ Cambridge, MA 02138 \\ April 1994
}

Lori Kaufman, Betsy McNair, and Kelly Welch provided able research assistance. Eugene Fama, Wayne Ferson, Wayne Mikkelson, Mark Mitchell, Kevin M. Murphy, Daniel Nelson, Mitch Petersen, Jay Ritter, Theo Vermaelen, and seminar participants at the NBER Summer Institute, Illinois, North Carolina, Oregon, Vanderbilt, and Washington provided helpful comments. This research is supported by the William Ladany Faculty Research Fund, the Center For Research in Security Prices (Kaplan), and the Division of Research at Harvard Business School (Ruback). This paper is part of NBER's research program in Corporate Finance. Any opinions expressed are those of the authors and not those of the National Bureau of Economic Research. 
NBER Working Paper \#4724

April 1994

\title{
THE VALUATION OF CASH \\ FLOW FORECASTS: AN \\ EMPIRICAL ANALYSIS
}

\begin{abstract}
This paper compares the market value of highly leveraged transactions (HLTs) to the discounted value of their corresponding cash flow forecasts. These forecasts are provided by management to investors and shareholders in 51 HLTs completed between 1983 and 1989 . Our estimates of discounted cash flows are within 10\%, on average, of the market values of the completed transactions. Our estimates perform at least as well as valuation methods using comparable companies and transactions. We also invert our analysis and estimate the risk premium implied by transaction values and forecast cash flows, and the relation of the implied risk premium to firm-level betas, industry-level betas, firm size, and firm book-to-market ratios.
\end{abstract}

Steven N. Kaplan

Graduate School of Business

University of Chicago

1101 East 58th Street

Chicago, IL 60637

and NBER
Richard S. Ruback

School of Business

Harvard University

Boston, MA 02163

and NBER 


\section{Introduction}

This paper compares the market value of management buyouts and leveraged recapitalizations to the discounted value of their corresponding cash flow forecasts. Most economists readily accept the concept of estimating market values by calculating the discounted value of the relevant cash flows. However, there is little preexisting empirical evidence that shows that discounted cash flows provide a reliable estimate of market value. This study provides evidence of a strong relation between the market value of the highly leveraged transactions (HLTs) in our sample and the discounted value of their corresponding cash flow forecasts.

Our tests compare the transaction values in HLTs to estimates of the present value of the relevant cash flows. We use a sample of management buyouts and leveraged recapitalizations because these transactions typically release the cash flow information and transaction value required for the analysis. We use the cash flow forecasts to estimate the cash flows that will accrue to all capital providers, including different classes of debt and equity. We estimate a terminal value when the cash flow information ends. We value the capital cash flows using a discount rate based on the CAPM. We use three CAPM-based approaches to estimate discount rates corresponding to firm-level, industry-level, and market-level measures of risk. Each of these approaches works well: the median estimates of discounted cash flows are within $10 \%$ of the HLT transaction values.

We compare the performance of our discounted cash flow estimates to that of estimates obtained from alternative valuation approaches that rely on companies in similar industries and companies involved in similar transactions. Such alternative valuation approaches - known as comparable approaches - are commonly used in practice. The discounted cash flow (DCF) methods, individually, perform at least as well as the comparable methods. We also find, however, that using the DCF and comparable methods together explains significantly more variation in transaction values than either method alone.

Overall, our DCF valuations generally parallel the basic techniques taught in most business schools. The fact that our resulting values are approximately equal to the 
transaction values suggests that the basic approach to valuation is both useful and reliable. We stress that our valuations rely on several ad hoc assumptions that readers (both academics and practitioners) should be able to improve on in a specific valuation. We would expect such improved assumptions to bring DCF valuations closer to transaction values.

We also invert our analysis to calculate an implied discount rate or internal cost of capital - the discount rate that equates the discounted cash flow forecasts to the transaction value. The median implied risk premium is $7.55 \%$ which is comparable to the historic arithmetic average risk premium. We also examine the relation of the implied risk premiums to firm size, firm book-to-market ratios, and systematic risk measures to determine if our results are consistent with Fama and French (1992) who find that firm equity returns are unrelated to firm-level measures of systematic risk when firm size and book-to-market ratios are taken into consideration. We find that the implied risk premiums are not significantly related to firm size nor to the pre-transaction book-to-market ratio. The implied risk premiums are positively related to firm and industry betas. For this sample, therefore, we favor CAPM-based approaches to discount rates over those based on size or book-to-market ratios.

The success of the discounted cash flow valuations is impressive because HLTs pose additional complications beyond the general concerns about capital market imperfections and intertemporal asset pricing models that arise in any valuation problem. First, the cash flow forecasts we rely on come from published legal filings and may not be constructed to be estimates of expected cash flows. Second, even if the cash flow forecasts are intended to be expected cash flows, the forecasting process is likely to involve substantial errors because major changes in organizational form and asset deployment accompany the HLTs. Third, since these firms have extremely leveraged capital structures, they may be limited in their access to capital markets and in their ability to use interest tax shields. Finally, the securities of these firms particularly high yield debt and private equity - are likely to be substantially less liquid than the liabilities of most large public corporations. Greater attention to these 
complications would presumably lead to better DCF valuations.

The success of the DCF valuation approaches in spite of the leveraged capital structures and overall complexity of the HLTs raises concerns that there is something special about our sample of HLTs. The primary concern is that the cash flows might somehow be endogenous, and that endogeneity causes the DCF valuations to be spurious estimates of transaction value. One potential source of endogeneity is that dealmakers and managers in the HLTs may have had incentives to adjust the cash flow forecasts. For example, incentives to bias the cash flow forecasts upward are present when the true expected cash flows are below the level required to obtain transaction financing. Incentive to bias the forecasts downward are present when the true expected cash flows are substantially above those needed to obtain financing. Because the SEC and courts effectively require the board of directors of the HLT company to obtain an opinion from an investment bank that the transaction price is "fair," insiders and dealmakers may have an incentive to reduce their reported cash flow forecasts to justify the transaction price.

We conduct several tests to gauge the magnitude of such adjustments. We examine the ex post accuracy of the cash flow forecasts and find little evidence of ex ante bias. We divide our sample into subsamples based on leverage and outside competition, and also find little difference across the subsamples. Finally, we use our DCF valuation technique to value initial public offerings where the leverage and incentives to adjust cash flow forecasts are different from those in our HLT sample. We find that the DCF valuations provide reliable estimates of value for the sample of initial public offerings. Overall, we find little evidence to suggest that the reliability of our DCF approaches is restricted to HLTs.

The paper proceeds as follows. Section 2 explains our basic valuation approach in more detail. Section 3 describes the data set along with some sample statistics. Section 4 presents the valuation results and compares those results to transaction values. Section 5 calculates implied risk premiums and compares them to firm betas, industry betas, firm size, and firm book-to-market ratios. Section 6 discusses 
and addresses potential criticisms of our results based on the incentives to adjust cash flow forecasts. Section 7 summarizes the results and presents our conclusions.

\section{Valuation Techniques \\ 2.1 Transaction Value}

In our analyses, we compare estimates of value to the transaction value. We define the transaction value as: (1) the market value of the firm common stock; (2) plus the market value of firm preferred stock; plus (3) the value of the firm debt; plus (4) transaction fees; less (5) firm cash balances and marketable securities. All of these are measured at the closing of the transaction. We value debt not repaid as part of the transaction at book value. Debt that is repaid is valued at the repayment value. Our measure of transaction value assumes that net working capital (excluding cash balances) and long-term assets are used to generate the cash flows of the firm. ${ }^{1}$

\subsection{The Compressed Adjusted Present Value Technique}

The Compressed Adjusted Present Value Technique (Compressed APV) that we use values firms by discounting capital cash flows at the discount rate for an allequity firm. ${ }^{2}$ Capital cash flows equal the after-corporate-tax cash flows to both debt and equity holders of the firm. Because the cash flows are measured after corporate tax, the tax benefits of deductible interest payments are included in the cash flows. The interest tax shields reduce income taxes, and, thereby, raise after-corporate-tax cash flows. Our use of the Compressed APV method is equivalent to using the adjusted

1 The sum of the market value of debt, preferred, and equity represents a claim on the value of a firm's future cash flows and the firm's current excess cash. We subtract cash balances and marketable securities as our estimate of excess cash, because our DCF estimates value future cash flows only. We obtain similar results when, instead, we subtract excess cash used to finance the transaction.

2 We would like to thank Stewart Myers for suggesting "Compressed APV" as a label for this method. 
present value (APV) method and discounting interest tax shields at the discount rate for an all-equity firm. This implicitly assumes that the interest tax shields have the same systematic risk as the firm's underlying cash flows. An alternative way to interpret the Compressed APV method is that of discounting the capital cash flows at the before-tax discount rate that is appropriate for the riskiness of the cash flows.

The Compressed APV method simplifies the valuation of HLTs. The widely used after-tax weighted average cost of capital (WACC) approach is appreciably more difficult to implement. The WACC approach requires that the cost of capital be recomputed each period to include the effect of changing leverage over time. It also requires additional assumptions about the firm's tax status to generate cash flows assuming an all-equity capitalization. ${ }^{3}$ The Compressed APV also has a computational advantage over the standard APV approach, because the standard APV approach requires that the all-equity cash flows and the interest tax shields be discounted separately at different discount rates.

\subsubsection{Measuring Capital Cash Flows}

We measure capital cash flows in two ways, depending on the presentation of the cash flow forecasts for the HLTs in our sample. The first method begins with net income. We add adjustments for the differences between accounting information and cash flows. These adjustments include depreciation, amortization, changes in deferred taxes, changes in net working capital, and interest. We add (before-tax) interest payments, subtract capital expenditures, and add the after-tax proceeds from asset sales.

3 See Ruback (1989) for additional background on the Compressed APV technique and its relation to the weighted average cost of capital approach. 


$$
\begin{aligned}
& \text { Net Income } \\
& \text { + Depreciation } \\
& \text { + Amortization } \\
& \text { + Change in deferred taxes } \\
& \text { - Change in net working capital } \\
& \text { + interest (cash and non-cash) } \\
& \text { - Capital expenditures } \\
& \text { + After-tax asset sales } \\
& \text { = Capital Cash Flows }
\end{aligned}
$$

Our second method for measuring capital cash flows begins with earning before interest and taxes (EBIT). We deduct corporate taxes which we estimate as the difference between EBIT and interest expense times the marginal tax rate. Information on the marginal corporate tax rate is provided in 33 of the HLTs in our sample. For the remaining 18, we calculate marginal corporate tax rates using the federal marginal tax rates expected to be in effect at the time of the transaction and a state tax rate of $5 \%{ }^{4}$ This calculation of taxes assumes that the HLT makes full use of interest tax shields. We also make the adjustments for differences between accounting information and cash flows, subtract capital expenditures and add after-tax proceeds from asset sales:

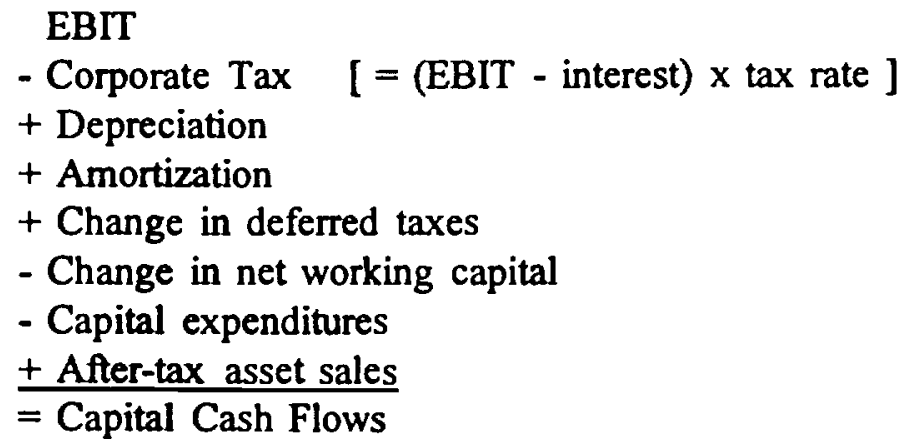

In our analysis, we prefer to use the first, net-income-based capital cash flow measure over the EBIT-based measure. The net-income-based measure utilizes estimates of future tax payments made by the HLT firm while the EBIT-based measure

4 For transactions completed before the Tax Reform Act of 1986 (TRA), we assume a federal tax rate of $46 \%$. For transactions completed after the TRA, we assume federal tax rates of $46 \%$ in $1986,38 \%$ in 1987 , and $34 \%$ thereafter. 
relies on our estimates of future tax payments. We use the EBIT-based method in the 15 HLTs in which information on projected taxes and net income is not available.

\subsubsection{Terminal Values}

We calculate terminal values as growing perpetuities by assuming that the capital cash flow in the last year of the forecasts will grow at a constant nominal rate in perpetuity. The growth rates should reflect both expected inflation growth and any real growth implicit in the cash flows.

Only 11 of 51 sample transactions explicitly note an expected inflation rate. The average expected inflation rate is $5 \%$. Actual inflation (as measured by growth of the GNP deflator) averaged 3.4\% per year between 1983 and 1989. In 1988, the year almost $50 \%$ of our transactions were priced, the GNP deflator increased by $3.3 \%$. We present our results using a nominal growth rate of $4 \%$, which corresponds to a real growth rate between $0 \%$ and $1 \%$. Although we feel the $4 \%$ rate is economically most appropriate, we also report the sensitivity of our results to different terminal cash flow growth rates.

On average, depreciation and amortization exceed capital expenditures in the capital cash flow used to calculate the terminal value. This is not a reasonable assumption. With $4 \%$ nominal growth in perpetuity, we expect capital expenditures to be slightly greater than depreciation and amortization. Accordingly, we adjust the capital cash flow of the terminal value in two different ways to correct this inconsistency: first, we set depreciation and amortization equal to capital expenditures; and second, we set capital expenditures equal to depreciation and amortization. We report the results using the first method, which we view as economically more appropriate. $^{s}$

s We obtain qualitatively similar results both when we use the second method and when we make no adjustment. 


\subsubsection{Discount Rates}

We discount the capital cash flows using the expected return implied by the Capital Aśset Pricing Model for the unlevered asset:

(3) $r^{\prime \prime}$

$$
=\quad r_{f}+\beta^{u} \times\left[r_{m}-r_{f}\right]
$$

where $r_{f}$ is the risk free rate, $\beta^{u}$ is the firm's unlevered beta or systematic risk, and $r_{m}$ $r_{f}$ is the risk premium required by investors to invest in a firm or project with the same level of systematic risk as the stock market.

We use the unlevered cost of capital because it is a reasonable estimate of the riskiness of the firm's assets. Our cash flow measure includes all of the cash flows generated by the assets, including interest tax shields. Under the assumption that the riskiness of these cash flows is the same as that of the firm's assets, the unlevered cost of capital is the appropriate discount rate using the Capital Asset Pricing Model. The unlevered cost of capital can also be interpreted as the before-corporate-tax, weighted average cost of capital. The before-tax discount rate is appropriate to discount capital cash flows because the tax benefits of interest are included in our cash flow measure. By adjusting the cash flows for taxes and applying Modigliani and Miller (1963), we can assume the weighted average cost of capital is the same for different levels of leverage and we do not have to estimate the cost of debt.

We present valuations using three different measures of systematic risk. First, we use a firm-based measure. We estimate equity $\beta^{\prime}$ 's, $\beta^{e}$, using daily stock returns, returns on the S\&P 500, and a Dimson (1979) correction. Returns are used from 540 to 60 days before the transaction is announced. To obtain $\beta^{\mu}$, we unlever $\beta^{e}$ : (4) $\beta^{\mathrm{a}}=\left[\beta^{\mathrm{e}} \times E+\beta^{\mathrm{p}} \times \mathrm{P}+\beta^{\mathrm{d}} \times \mathrm{D}\right] /[\mathrm{E}+\mathrm{P}+\mathrm{D} \times(1-$ Tax Rate $)]$ where $\mathrm{E}$ equals the market value of firm equity 60 days before the transactions is announced, $P$ equals the (book) liquidation value of non-convertible preferred stock, and D equals net debt - the book value of short-term and long-term debt, less cash and marketable securities at the time of the transaction. We assume the systematic risk of the preferred stock and the debt, $\beta^{p}$ and $\beta^{d}$, with respect to returns on the S\&P 500 equal 0.25 - the beta reported for high grade debt from 1977 to 1989 in Comell and Green 
(1991). ${ }^{6}$ Finally, the tax rate equals the combined marginal federal and state tax rate during the estimation period.

Second, we use an industry-based measure of systematic risk. We calculate industry equity betas using daily returns from a value-weighted portfolio of all New York and American Stock Exchange companies in the same two-digit SIC code as the sample companies. The industry equity betas are calculated from 540 to 60 days before the transaction is announced using retums on the S\&P 500, and a Dimson (1979) correction. We use (4) to unlever the industry equity betas with the value-weighted ratios of equity, preferred, and debt to total capital for firms in the relevant industry. These industry ratios are calculated using COMPUSTAT data for the fiscal year ending before the HLT is announced.

Third, we use a market-based measure of systematic risk in which we assume that the systematic risk for all sample firms equals the risk of the assets of the market. To obtain the market asset beta, we calculate the leverage of non-financial and nonutility firms in the S\&P 500 using the definition from (4). The median leverage ratio during the sample period, 1983-1989, was 0.20. Combining the market leverage in the year before the transaction and a debt beta of 0.25 , the median unlevered asset beta for the market equals 0.93 .

We calculate risk premiums as the arithmetic average return spread between the S\&P 500 and long-term Treasury bonds from 1926 until the year before the transaction is announced. For our sample firms, the median risk premium is $7.42 \%$. In using this risk premium, we implicitly assume that the experience of the previous 60 years (or so) is the best predictor of the future. Some readers may view this assumption as overly aggressive. Blanchard (1994), for example, argues that the risk premium declined to $3 \%$ to $4 \%$ by the end of the 1980 s. We follow the general practice in finance texts in using the historical risk premium. [For example, see Brealey and Myers

6 Given that the preferred stock is not convertible, we view this as a reasonable assumption. In any case, this will have a small impact on the results because only 7 of the sample companies have any such preferred outstanding. 
(1991)]. The reasonableness of our choice is an empirical question that we implicitly test in section 4 and explicitly consider in section 5 . We also use the long-term Treasury bond (approximately 20 years to maturity) yield to measure the risk-free rate in our cost of capital calculations. Long-term Treasury bond yields, by month, are obtained from Ibbotson Associates (1991).

Our specifications implicitly assume a long-term investment horizon. However, we obtain qualitatively similar results when we base our analyses on a shortterm investment horizon. For a short-term horizon, we estimate the risk-free rate as the long-term Treasury bond yield less the historic arithmetic average spread between Treasury bond and Treasury bill returns, and we use a risk premium equal to the longterm arithmetic average return spread between the S\&P 500 and Treasury bills.

\subsection{Valuation Methods Using Comparables}

Practitioners often value companies using trading or transaction multiples. In these methods, a ratio of a performance measure like EBITDA to value is calculated for a set of guideline or comparable firms. Value is estimated by multiplying the ratio from the guideline companies by the performance measure for the company being valued.

Valuation by comparables or multiples relies on two assumptions. First, the comparable companies have proportional future cash flow expectations and risks as the firm being valued. And second, the performance measure (like EBITDA) is actually proportional to value. If these assumptions are valid, the comparable method will provide at least as accurate a measure of value as any discounted cash flow approach because it incorporates contemporaneous market expectations of future cash flows and discount rates in the multiple. In practice, however, the comparable companies are not perfect matches in the sense that cash flows and risks are not proportional. Also, there is no obvious method to determine which measure of performance - EBITDA, cash flow, net income, and so on - is the appropriate basis of comparison. Consistent with these concerns, Kim and Ritter (1994) find that comparable methods are not particularly successful in pricing initial public offerings. 
The discounted cash flow method relies on forecast cash flows which directly relate to the firm being valued and discount rates which are based on the historical riskiness of the company (in the firm beta valuations) or industry (in the industry beta valuations) being valued. The reliability of the discounted cash flow valuation depends on the accuracy of the cash flow projections, risk measures, and the assumptions used in calculating the cost of capital, including the historical measure of the risk premium. Both the discounted cash flow methods and the comparable firm methods therefore have inherent estimation errors. The empirical issue is whether the firm-specific information used in the discounted cash flow method offsets the lack of contemporaneous measures of market expectations contained in the comparable methods.

To make the values estimated with multiples comparable to those estimated using capital cash flows, we base our multiples on EBITDA. We use three different measures of guideline or comparable companies. The first, which we label comparable company, uses a multiple calculated from the trading values of firms in the same industry as the firm being valued. The second, which we label comparable transaction, uses a multiple from companies that were involved in a similar transaction to the company being valued. The third, which we label comparable industry transaction, uses a multiple from companies in the same industry that were involved in a similar transaction to the company being valued.

We construct comparable company value as the sample firm's EBITDA in the year before the transaction multiplied by the median industry multiple of total capital value in the month of the transaction to EBITDA in the year before the transaction. Total capital value is the analog of transaction value, equalling the sum of the market value of common stock, the liquidation value of firm preferred stock, and the book value of firm short- and long-term debt, less the cash balances and marketable securities of the firm. To get as close a match as possible, we calculated the industry multiples using companies with the same four-digit SIC code and with total capitalizations of at least $\$ 40$ million. If we found fewer than five comparable companies, we repeated the calculation at the three-digit level, and, if necessary, at the two-digit level. 
We calculate comparable transaction value as the sample firm's EBITDA in the year before the transaction times the median ratio of total transaction value to EBITDA (in the year before the transaction) for comparable HLTs. Comparable HLTs are those HLTs among the 136 in Kaplan and Stein (1990 and 1993) that are priced within one year of the date the sample transaction is priced.

Comparable industry transaction values combine the comparable company and comparable transaction approaches by estimating comparable transaction values for HLTs in the same industry. We use the sample firm's EBITDA in the year before the transaction times the median multiple of total transaction value to EBITDA in the year before the transaction for HLTs in the same 2-digit SIC code that are priced within two years of the date the sample transaction is priced. We are unable to obtain an acceptable comparable industry HLT for more than one-quarter of the HLTs (13 of 51), and, therefore, the sample size for this measure is lower. Because the sample from which we draw the comparables includes a large fraction of the HLT universe, we do not believe this is a sample specific problem.

3. Data

Our sample of companies starts with two sources of highly leveraged transactions. First, we use the sample of 124 management buyouts (MBOs) analyzed by Kaplan and Stein (1993). These buyouts met four conditions: (1) the companies are originally publicly owned; (2) the transaction is completed between 1980 and 1989 ; (3) at least one member of the incumbent management team obtains an equity interest in the new private firm; and (4) the total transaction value exceeds $\$ 100$ million.

We add to this the sample of 12 leveraged recapitalizations examined by Kaplan and Stein (1990). A leveraged recapitalization is similar to a MBO in many respects except that it does not involve the repurchase of all of a company's stock. While there is a dramatic increase in leverage, public stockholders retain some interest in the company. These leveraged recapitalizations were completed between 1985 and 1989. 
We study these transactions because they are subject to Rule 13E-3 of the Securities and Exchange Act. Rule 13E-3 applies to transactions in which insiders potentially stand to benefit at the expense of outside, public shareholders. Item 8 of Rule 13E-3 requires the HLT's board of directors to indicate whether that the transaction is fair (or unfair) to public shareholders, and to provide a detailed discussion of the basis for that opinion. Item 9 further requires the HLT board to furmish a summary of any report or appraisal from an outside party that relates to the opinion in Item 8. The disclosure in Item 9 usually includes some cash flow forecasts.

We examined the documents describing the transactions that these firms filed with the SEC. These documents include proxy statements, Schedule 14D tender offer filings, and Schedule 13E-3 filings. All but 12 of the 136 companies provide some post-transaction financial projections or forecasts. Unfortunately, the forecasts do not always include enough information to do a complete valuation.

We include in our sample those companies that provide at least four years of post-transaction projections for (1) operating income before interest, depreciation, amortization, and taxes; (2) depreciation and amortization; (3) capital expenditures; (4) change in net working capital. These cash flows are the minimum required to calculate the capital cash flows. In two additional cases, commercial bankers provided us with projections distributed by buyout promoters at the time of the transaction that were not available in SEC documents. We obtained the required information for 51 of the 136 HLTs. Twenty-two of these companies provide ten years of cash flow projections; three, nine years; three, eight years; one, seven years; seven, six years; fourteen, five years; and one, four years.

Table 1 shows the number of transactions with complete projections by year of the transaction. This sample is time-clustered. Almost one-half of the transactions were completed in 1988. All but six of the transactions were completed between 1986 and 1989. Table 1 also distinguishes between MBOs and recapitalizations: forty-three transactions are MBOs while eight are recapitalizations.

Finally, table 1 reports that in thirty-three transactions, the financial projections 
explicitly state that they reflect the buyout or recapitalization. The remaining eighteen state that the projections do not reflect the transaction. Unfortunately, the meaning of this statement is not always clear. Not reflecting the transaction may simply mean that the projections do not reflect the proposed capital structure. Alternatively, the projections may not reflect expected operating changes. The compressed APV estimates for the 33 forecasts that reflect the transactions tend to have lower mean squared and mean absolute errors than those for the 18 forecasts that are ambiguous. These differences, however, are not statistically significant.

For each transaction with complete projections, we obtain information describing the transactions from proxy, 13E-3, or 14D statements. Stock prices two months before the transaction announcement and at transaction completion are obtained from the Center for Research in Security Prices (CRSP) database and Standard \& Poor's Daily Stock Price Record. Other financial data are obtained from the COMPUSTAT Tapes. For more details on these transactions, see Kaplan and Stein (1990 and 1993).

In section 6, we address possible endogeneity issues by performing similar analyses for cash flow forecasts of a smaller sample of eight initial public offerings (IPOs) completed between October, 1991 and July, 1992. The IPO firms are firms that had previously gone private in leveraged buyouts. These cash flow forecasts are not available in SEC documents. Because the IPOs involved refinancing existing loans, the IPO firms provided cash flow forecasts to commercial bankers who held the loans, and we obtained the forecasts from those bankers.

\section{Valuation Results.}

\subsection{Compressed APV Methods}

Panel I of table 2 presents summary statistics for the valuation or estimation errors of the three discounted cash flow and three comparable valuation methods. The errors are computed as the $\log$ of the ratio of our estimated values to the transaction value. Because we present the errors in percent, they can be interpreted as the percentage differences between the estimated value and the transaction value. For 
example, focusing on the Compressed APV estimate using firm-specific betas, the median error is $6.0 \%$ which means that DCF estimate is $6.0 \%$ greater than the transaction value. Across the Compressed APV measures, the median errors are $3.2 \%$ when industry-based estimates are used, and $1.0 \%$ when market-based estimates are used. The mean errors are similar with the firm-based estimates overestimating transaction values the most, industry-based estimates exhibiting less of an over-estimate, and market-based estimates being closest to transaction value. The variation in the valuation errors is greatest for the firm-based beta estimates, as well.

The errors across the Compressed APV methods are related to the estimated asset betas. The median firm-based asset beta is $\mathbf{0 . 8 5}$, which is smaller than the median industry-based asset beta of $\mathbf{0 . 8 8}$, which, in turn, is smaller than the median marketbased asset beta of 0.93 . A higher beta increases the discount rate which in turn decreases the estimated value. Across the methods of estimating beta we examine, the higher the beta, the lower the estimated error.

The sensitivity of valuation errors to beta suggests that recommendations to use lower risk premiums and higher terminal value growth rates would reduce the accuracy of discounted cash flow estimates of value. Panels II and III of table 3 show that this is the case by reporting the sensitivity of our valuation errors to changes, respectively, in the risk premium and terminal value growth rates. For example, if we use a risk premium of $6 \%$, the median errors increase to $15.9 \%$ for the firm-based beta estimates, to $14.1 \%$ for the industry-based estimates, and to $12.4 \%$ for the market-based estimates. In contrast, when a higher risk premium is used, such as $9 \%$, the median errors of the firm-based, industry-based, and market-based errors decline, with errors of $-3.3 \%,-6.3 \%$, and $-9.2 \%$, respectively.

We also experimented with beta estimation techniques that adjust for the tendency of betas to regress to the mean in future periods. ${ }^{7}$ These adjustments included using (1) equity betas equal to an equal weighted average of the firm or industry beta

7 See Blume (1975) and Klemkosky and Martin (1975). 
and the market beta, i.e., estimates that push the firm or industry equity betas closer to one; (2) the Bayesian approach in Vasicek (1973) which estimates equity betas as a weighted average of firm equity betas and the sample mean using the historical distribution of the sample beta coefficients; and (3) the Bayesian approach in Stevens (1993) which estimates equity betas using information in firm equity betas and industry betas. These methods are basically weighted averages of the methods we present in Table 2 , and the results using these different techniques are roughly combinations of those reported in Table 2.

\subsection{Comparable Methods}

Panel I of Table 2 also reports the valuation errors when value is estimated using the three comparable methods. The estimates based on the comparable company method substantially underestimate transaction value, with a median estimation error of $-18.1 \%$. This is well outside the range of median errors for the Compressed APV methods.

The comparable transaction based estimates are more accurate, with a median error of $5.9 \%$, which is in the range of median errors for the Compressed APV estimates. In fact, the mean valuation error of $0.3 \%$ for the comparable transactions is lower than the mean valuation error for the Compressed APV estimates. The most accurate estimates are those for the comparable industry transaction method with median and mean valuation errors below $1 \%$. This method has the highest standard deviation, however, suggesting that the accuracy varies across firms in the sample. Furthermore, the results highlight the fact that the method is not generally applicable because it is difficult to match both the industry and the transaction. As noted above, we were unable to find matches for 13 of the 51 firms in our sample during a period in which there were a relatively large number of HLTs. In other samples and time periods, we suspect this problem would be even worse. This method also is difficult to generalize to other common valuation problems, such as capital investment decisions, because there is typically no transaction to match. 
We also examined (but do not report in the tables) a hybrid approach in which we use the capital cash flows in the forecast period and the comparable company EBITDA multiple to estimate the terminal value - multiplying it by the EBTDA forecast in the final year of the projections. We then discount the capital cash flows and terminal value at the discount rate for one of the three APV approaches. This approach yields estimated values that are significantly higher than the transaction values. For example, using a market-based discount rate, we find that the median estimated value exceeds the transaction value by $18.1 \%$. One explanation for the poor performance of this hybrid is that the EBITDA multiple at the time of the transaction includes a weighted average of higher growth during the forecast period and lower growth after the forecast period. By using the cash flows forecast over the forecast period and then applying the EBITDA multiple at the end of the period, the hybrid approach effectively double counts the higher growth during the forecast period.

\subsection{Comparative Performance of Valuation Methods}

The previous results suggest that both the Compressed APV and the comparable valuation methods are useful in estimating transaction values. In this section, we compare the Compressed APV and comparable valuation methods in greater detail, using four measures of performance. The first three measures take an ex ante perspective and assume that the transaction value is the "true" value. These measure are also symmetric because they assume that under- and over-valuations are equally costly. Because they are based on market prices, we view these three ex ante measures as the most appropriate for judging the performance of the valuation methods. Nevertheless, we also present a fourth performance measure that makes use of ex post outcomes and, therefore, does not assume that the transaction value is the "true" value.

\subsubsection{Percentage of Transactions Within 15 Percent}

Panel II.1 of table 2 reports the percentage of transactions in which the absolute value of the valuation error is less than or equal to $15 \%$. Although it is 
somewhat arbitrary, we interpret a $15 \%$ error as a "small". error - smaller than the typical premiums of $40 \%$ or greater associated with these transactions, and smaller than the factor of two used in Black (1986) to define efficiency. (Our results are similar when we use windows of $10 \%$ or $20 \%$.)

The estimates using the firm-based Compressed APV method are within 15\% of transaction value for almost one-half of the sample. The industry-based and the market-based estimates do better, with more than $60 \%$ of the estimates within $15 \%$ of transaction value.

The comparable company method and comparable transaction estimates are less successful than the Compressed APV methods. Only $37 \%$ of the comparable company values and $47 \%$ of the comparable transaction estimates are within $15 \%$. The percentages for the industry-based and market-based APV methods are significantly greater (at the $10 \%$ level or better) than those for the comparable company method. The percentage for the industry-based APV method is also significantly greater than that for the comparable transaction method.

In the 38 transactions for which we can apply the comparable approach that matches both industry and transaction, $58 \%$ of the valuation errors are less than $15 \%$. This comparable method therefore has about the same percentage of errors within $15 \%$ as the Compressed APV methods.

\subsubsection{Mean Absolute Error}

The second performance measure is the mean absolute error of the valuation errors (MAE). This assumes that under- and over-valuations are equally costly and that the cost of valuation errors increases linearly. The MAE is $20 \%$ for the Compressed APV using the firm-based betas, and less than $17 \%$ for the estimates using industry- and market-based betas. The comparable methods have generally higher MAEs; $24.7 \%$ for company-based comparables, $18.1 \%$ for transaction-based comparables, and $20.5 \%$ for industry- and transaction-based comparables. The MAEs of the industry- and marketbased APV methods are significantly smaller than the MAE of the comparable company 
method.

\subsubsection{Mean Squared Error}

Our third measure is the mean squared error of the valuation errors (MSE). This assumes that under- and over-valuations are equally costly and that the cost increases are quadratic. Using this measure, the comparable company and the comparable industry transaction methods perform poorly - with higher mean squared errors than any APV method. The comparable transaction method, in contrast, does best, performing slightly (but insignificantly) better than the industry-based method (MSE of 5.5\%) and the market-based method (MSE of 5.0\%). The comparable company method MSE is significantly greater than the market-based method MSE and the comparable transaction MSE.

\subsubsection{Summary of Ex Ante Measures}

We conclude, based on the results presented in Table 2, that the Compressed APV techniques provide a reasonable and accurate measure of value. The median and mean estimation errors are below $6.3 \%$ for all Compressed APV methods. And the valuation errors have a strong tendency towards zero, with about $50 \%$ or more of the estimated values being within $15 \%$ of the transaction value. If we had to choose among the three Compressed APV methods, we would pick the industry-based or market-based beta approaches. The Compressed APV method using these two approaches have a roughly equal ability to predict transaction values.

Among the comparable methods, the comparable firm method performs poorly in every dimension. It is the least reliable valuation method we examine. The comparable transaction along with the comparable method matching industry and transaction work better than the comparable firm method, and, work almost as well as the Compressed APV methods.

We favor the Compressed APV methods for three reasons. First, the Compressed APV methods have more valuation errors within 15\%, and lower MAEs 
and MSEs. Second, we think that in practice participants are likely to have access to better estimates of cash flows and other inputs into the Compressed APV method than we have had available to us. On the other hand, we think that our information on comparables - especially on comparable transactions - is close to the information that would have been used in practice. Thus, we think practical application of the Compressed APV method will improve its accuracy. Third, the comparable methods that work best are based on transactions, and therefore have little applicability beyond a transaction context. In contrast, the Compressed APV method can be used in a variety of corporate finance applications. This criticism is relevant even in the current sample for the comparable industry transaction method because that method fails to produce estimated values for more than one-quarter of the sample HLTs.

\subsubsection{Performance Based on Outcomes}

Our final measure of performance makes use of ex post evidence on whether the sample companies have defaulted on their debt after the transaction. As of December 1993, 17 of the 51 sample companies had defaulted. This is a noisy measure of transaction success from the viewpoint of lenders and equity investors. Some transactions that have not defaulted may default in the future or yield low returns to their investors. This measure is also noisy in that it is almost sure to reflect events that were not expected at the time of the HLTs.

Our performance measure is the percentage of mistakes made by the various methods based on ex post outcomes. The estimated values can be mistaken in two ways. First, if the estimated value exceeds the transaction value and the HLT subsequently defaults on its debt payments, the estimated value accepted a bad deal. Second, if the estimated value is less than the transaction value and the HLT does not default on its debt payments, the estimated value rejected a good deal. Our ex post measure of mistakes places no weight on how far the estimated value is from the transaction value.

In panel II of table 2, the firm-based Compressed APV method and the 
comparable industry transaction method make the smallest percentage of errors, ex post; the market-based Compressed APV method makes the most. Even the best of these methods is mistaken more than $40 \%$ of the time. Overall, the Compressed APV methods and comparable methods perform about equally well (or badly). The only significant difference is that between the percentage of errors of the market-based Compressed APV method and the comparable industry transaction method. Again, however, the performance of the comparable industry transaction method is overstated because the method fails to produce estimated values for more than one-quarter of the sample HLTs.

\subsection{Cross-sectional Relation of Estimated Values to Transaction Values}

The results in the previous sections focus on how well the Compressed APV and comparable valuation approaches estimate the actual transaction value level. It is possible, however, that one of the approaches could successfully estimate the transaction value on average, yet perform poorly in explaining the variation in transaction values. The converse is also possible. In this section, we consider these possibilities by estimating regressions to determine how well the different valuation methods explain the variation in transaction values. With a regression approach, we can also test whether using the DCF and comparable approaches together can explain additional variation.

The regressions relate transaction values to estimated values from the Compressed APV and comparable methods. The basic model we want to estimate is: (5) Transaction Value $=\alpha+\beta$ Estimated Value $+\varepsilon$ If the estimated values are unbiased predictors of transaction value, the coefficient estimates for the intercept will be zero and for the slope, will be one. The key question with this model is the specification. It seems likely that the intercept term and the error term will be related to value or size. Accordingly, we present two specifications. First, we regress the $\log$ of transaction value on the log of estimated value. This assumes that the residuals from the model are proportional to value. Second, we eliminate size 
entirely by regressing the transaction value as a multiple of EBITDA on estimated value, again expressed as a multiple of EBITDA.

Column 1 of Table 4 presents the regression results for the $\log -\log$ specification. The estimates from the three Compressed APV approaches in column 1 are consistent with the approach providing unbiased estimates of transaction values. The intercepts are all insignificantly different from zero, and the slopes are all insignificantly different from one. Furthermore, the estimated values explain virtually all the variation in transaction values and the residuals from the log-log specification are well-behaved - there is no evidence of heteroscedasticity or undue influence from large observations. Again, the Compressed APV methods perform at least as well as the comparable methods. The comparable value methods explain a similar amount of variation in transaction value, but the intercepts are larger. In fact, the intercept in the comparable company regression is significantly larger than 0 , indicating it is a biased estimator of transaction value.

It is possible that the different valuation approaches contain different information about transaction values. Accordingly, column 2 presents estimates of a regression that includes as independent variables the market-based Compressed APV values, the comparable company values, and comparable transaction values. All three variables are statistically significant, the intercept term is not significantly different from 0 , and the variables together explain a bit more variation in transaction value than any one of them does alone.

In some sense, however, the DCF and comparable approaches are too successful in explaining the variation in transaction values using the log-log specification. Although the residuals in the regressions are well-behaved, the log-log specifications may perform so well because they regress measures of size on size. For the second set of regressions, we eliminate size by scaling transaction values and

${ }^{8}$ We do not present regressions using the comparable industry transaction estimated values because the regressions include only 38 observations and because those values explain less variation in transaction value than the other two comparable methods. 
estimated values by EBITDA in the year before the transaction. We then regress the resultant transaction value multiples on the estimated value multiples:

(6) Transaction Value Multiple $=\alpha+\beta$ Estimated Value Multiple $+\varepsilon$

This specification is particularly interesting because it was customary to price HLTs as multiples of EBITDA. [See Kaplan (1989b) and DeAngelo (1990)].

Table 4 presents results of both log-log and level-level specifications for these regressions. Again, we prefer the $\log$-log specification because it assumes a more reasonable multiplicative error structure. In column 3, the estimates from the three APV approaches explain from $35 \%$ to $46 \%$ of the variation in the transaction multiples. The industry-based approach explains the most variation; the firm-based approach, the least. In contrast, the comparable company and comparable transaction multiples explain much less of that variation, respectively, $22 \%$ and $9 \%$. Although not reported the comparable industry transaction multiples explain only $5 \%$ of the variation.

While they explain an impressive amount of variation in transaction multiples, there is one respect in which the Compressed APV multiples may seem disappointing. The constant terms in the regressions differ significantly from zero and the slope coefficients differ significantly from one. The likely explanation is that the constant term measures the contribution of EBITDA in explaining transaction value. This can be seen by multiplying (6) by EBITDA to recast the regression in levels:

(6') Transaction Value $=\alpha$ EBITDA $+\beta$ Estimated Value $+\varepsilon^{\prime}$ If, as is likely, the estimated values are measured with some error, and EBITDA is correlated with the estimated values, $\alpha$ in (6) will not equal zero, and $\beta$ will note equal one. (We also estimated the reverse regressions in which the transaction value is the independent value and the estimated values are the dependent variables. In those regressions, only one slope coefficient in the APV estimate reverse regressions, that using the market-based APV values, differs significantly from one, at the $10 \%$ level, whereas the slope coefficients in all of the comparable estimate reverse regressions do.)

In column 4 (and column 6 ) of table 4 we present the results of a regression that, again, includes the market-based APV multiples, the comparable company multiples, and the comparable transaction multiples. The APV and comparable 
multiples together explain almost $50 \%$ of the variation in transaction multiples. The coefficients indicate that the APV and comparable company methods both have significant explanatory power for transaction multiples. Although the comparable transaction multiple has the largest coefficient, that coefficient is not significant. Again, these regression results suggest that it is worthwhile to combine the information in the APV and comparable approaches.

Overall, the univariate regression results indicate that the APV approaches perform well relative to the comparable approaches in explaining variation in transaction values and multiples. The APV approaches are individually superior to the comparable approaches in explaining the variation in transaction multiples. We interpret these results as additional evidence in favor of the usefulness of the discounted value approaches. Choosing among the three APV methods, we prefer the industry-based and market-based approaches. These approaches perform well in estimating both the level of the transaction value and in explaining variation in transaction value.

\section{Implied Cost of Capital}

In this section, we revisit the risk premium which is used in our Compressed APV calculations. We devote special attention to the risk premium because there is substantial debate about how the risk premium should be measured. Some rely on the method we prefer which is a long-term arithmetic average of the historical spread between a market index and riskless bonds. Others prefer (incorrectly, in our opinion) a geometric average over a long or short time period. These methods provide substantially different measures of risk premiums. For example, the geometric average spread is $5.41 \%$ which is roughly $2 \%$ below the median arithmetic average spread we use of $7.42 \%$.

We invert are analysis to derive the discount rates implied by the transaction

values to provide direct empirical evidence about the risk premium. We use the same forecast capital cash flows and terminal values to calculate an implied discount rate or cost of capital which equates the estimated value to the transaction value. The implied 
risk premium equals the difference between the implied discount rate and the yield on long-term Treasury bonds at the time of the projections. The implied risk premium represents the product of the implied market equity risk premium and an asset beta. We estimate an implied market equity risk premium by dividing the implied risk premium by our market-based asset beta (where the market-based asset beta is calculated using the value weighted capital structure for non-financial, non-utility firms in the S\&P 500 in the fiscal year before the HLT announcement).

\subsection{Implied Discount Rates, Risk Premiums, and Market Equity Risk Premiums}

Using our assumption of $4 \%$ growth in calculating terminal values, table 5 reports that the median implied discount rate for the 51 HLTs is $15.77 \%$, the mean is $16.28 \%$, and the standard deviation is $2.69 \%$. The implied risk premium, calculated by subtracting the contemporaneous long-term Treasury bond yield has a median of $7.07 \%$, a mean of $7.14 \%$, and a standard deviation of $2.76 \%$. The median implied market equity risk premium is $7.55 \%$, the mean is $7.74 \%$, and the standard deviation is $2.95 \%$. We do not find any variation over time in the implied market equity risk premiums. Admittedly, such variation might be hard to detect given the clustering of our sample in the late $1980 \mathrm{~s}$.

Table 5 also presents implied discount rates, risk premiums, and market equity risk premiums assuming terminal value growth rates of $6 \%, 2 \%$, and $0 \%$. Not surprisingly, the risk premiums vary with the terminal value growth rate. The implied market equity risk premium drops to $5.00 \%$ with no terminal value growth and increases to $8.81 \%$ with $6 \%$ terminal value growth. As we noted earlier, we feel that a $4 \%$ growth rate is the economically most plausible assumption.

Like the evidence in section 4 , the risk premium results strongly suggest that the Compressed APV technique works best when an arithmetic average risk premium is used. The estimated market equity risk premium is remarkably close to the $7.42 \%$ median risk premium (calculated using the long-term arithmetic average of the spread 
between the S\&P 500 index and long-term Treasury bonds) we use for our Compressed APV estimates. There is no evidence that the use of lower risk premiums, however obtained, would improve the accuracy of discounted cash flow techniques.

\subsection{Relation of Implied Risk Premiums to Systematic Risk, Size, and Book-to-Market}

In this section, we examine the relation between our implied risk premiums and (1) firm asset betas; (2) industry asset betas; (3) transaction size; and (4) company book-to-market ratios (in the fiscal year ending before the transaction is announced). Our examination is motivated by two findings. First, Fama and French (1992) report that equity returns are negatively related to firm size, positively related to the book-tomarket ratio and, controlling for firm size and book-to-market ratio, unrelated to equity betas. Second, our results, reported in section 4 , indicate that the Compressed APV method using market-based betas works about as well as industry-based betas. Both of these results are contrary to the generally accepted notion that expected returns are related to systematic risk. By examining the determinants of the individual implied risk premiums in our sample, we provide evidence on how the market determines expected returns. We use pre-transaction book-to-market ratios because book-to-market ratios at the time the transaction is completed equal one for all management buyouts and are typically negative for leveraged recapitalizations. ${ }^{9}$

Table 6 presents univariate regressions of the risk measures on the implied risk premium. The regressions indicate that the implied risk premium is positively related to both beta measures. In the two univariate regressions, neither of the coefficients on the betas is statistically significant at the $10 \%$ level (using a two-tailed test). The insignificance of the regression coefficient for the industry beta appears to be caused by outliers. Non-parametric rank tests indicate that the risk premium is significantly related

${ }^{9}$ In our regressions, we exclude observations with negative pre-transaction book-tomarket ratios. 
to industry betas (at the $5 \%$ level).

While the risk premiums are marginally related to the betas, table 6 indicates that the implied risk premiums are not related to firm size -- (the log of) transaction value - or to the pre-buyout book-to-market ratio. Non-parametric rank correlations also fail to identify any significant relation between the risk premium and either size or the book-to-market ratio.

The patterns are qualitatively similar when one of the betas, size, and book-tomarket ratios are included in the same regression. In fact, the firm asset beta becomes significant at the $10 \%$ level in the multiple regression. Overall, these results suggest a positive relationship between expected returns and systematic or beta risk, but provide no basis for concluding that discounted cash flow valuations could be improved by basing discount rates on firm size or market-to-book ratios.

\section{Potential Endogeneity or Hardwiring of Cash Flow Forecasts.}

The previous sections indicate that the Compressed APV valuation approaches provide reasonably accurate estimates of transaction values. This is somewhat surprising because HLTs provide significant valuation challenges because of their high levels of debt. The success of the Compressed APV approaches in valuing these complex HLTs raises the question of whether there is something special about our sample of HLTs that makes the Compressed APV technique so effective, and whether there are reasons to doubt that the APV methods will work as well in practice as they do in our tests.

The primary concern is that the cash flows might somehow be endogenous, and that the endogeneity causes the Compressed APV valuations to be spurious estimates of transaction value. One potential source of endogeneity is that dealmakers and managers in the HLTs in our sample may have had incentives to adjust the cash 
flow forecasts. ${ }^{10}$ If the transaction value and financial structure are determined by competition in the market for corporate control, dealmakers may have an incentive to construct their cash flow forecasts to justify the price and to convince lenders and investors to finance the transactions. The transaction value and financial structure imply a sequence of required interest and principal payments, and the forecast cash flows have to exceed those debt payments for the transaction to be feasible. Because the sample transactions are largely debt financed (a median $88 \%$ of transaction value), cash flows that are constructed to exceed debt payments would be "hardwired" in the sense that cash flows are constructed so that their present value will yield the transaction value.

One implication of hardwiring is that the cash flow forecasts are adjusted upward or downward to approximate the required debt payments. Incentives to bias the cash flow forecasts upward may occur when true expected cash flows are below the level required to obtain financing. Incentives to bias the cash flows downward may occur when the true expected cash flows are substantially in excess of those required to obtain financing. Because the SEC and courts require the HLT firm's board of directors to obtain an opinion from an investment bank that the transaction value is "fair," insiders and dealmakers may have an incentive to reduce their reported cash flow forecasts to justify the transaction value.

As an illustration of hardwiring, consider a typical HLT that finances $55 \%$ of transaction value with bank debt at a nominal rate that exceeds the Treasury bond rate by $1.5 \%$; approximately $35 \%$ of transaction value with subordinated debt at a nominal rate that exceeds the Treasury bond rate by $4.5 \%$; and approximately $10 \%$ of transaction value with equity at an unknown rate of return over the Treasury bond. Assuming

10 For example, although it is not in our sample, there is some evidence that the managers at Interco made such adjustments during the financing of their leveraged recapitalization. See "Fiction in, Fiction out" by Laura Jereski, Forbes, December 9, 1991, page 292. See also Burrough and Helyar (1990) for a description of how cash flows were forecast in the RJR Nabisco buyout. 
equity yields a nominal return at least $4.5 \%$ over the Treasury bond, hardwiring would put a lower bound on the internal rate of return equal to the Treasury bond yield plus $2.85 \%$.

The Treasury bond yield plus $2.85 \%$ is substantially below the implied discount rate (the Treasury bond yield plus $7.07 \%$ ) that we estimate in Section 5, suggesting that our basic empirical findings are not confounded by hardwiring. Furthermore, hardwiring implies that all parties -- investors, courts, investment banks, etc. - use methods like Compressed APV to determine the transaction value. Although we doubt that the Compressed APV method works simply because everyone uses it, we take the hardwiring criticism seriously and perform four additional tests for evidence of hardwiring.

\section{I Ex post Accuracy of Cash Flow Forecasts}

If the forecast cash flows are biased either upward or downward, there should be differences between the forecasts and the realizations. This is difficult to test because we know of no method to directly measure the ex ante bias, if any, in the forecasts. We rely, therefore, on ex post data to gauge the accuracy of the forecasts. Using ex post data to assess the forecasts is, however, complicated because the U.S. economy entered a recession in 1990 , less than two years after the majority of these transactions. The forecasts were unlikely to anticipate the recession and thus, even if the forecasts were unbiased ex ante estimates of expected cash flows, we anticipate that the actual cash flows will exceed the forecasts. Nevertheless, we examine the ex post accuracy of the projections by comparing forecast EBITDA to post-transaction EBITDA. We also examine EBITDA margins because the recession as well as asset sales not considered in the projections should have had less effect on margins.

We are able to obtain at least one year of post-transaction data for 46 of the 51 sample HLTs. In the first and second complete fiscal years after the HLT, EBITDA levels are, respectively, a median of $3.7 \%$ and $14.4 \%$ below those forecast, both of which are statistically significant at the $5 \%$ level. This is consistent with optimistic 
cash flow forecasts caused by either ex ante optimism or an unanticipated recession. In contrast, we find only weak evidence that forecast EBITDA margins are biased. EBITDA margins are below those forecast by a median of $3.2 \%$ and $3.6 \%$ of the forecast margin, respectively, in the first and second years after the transaction. (If EBITDA margins were forecast to equal $20.00 \%$ of sales, a $3.6 \%$ shortfall in margins is equivalent to actual margins being $19.28 \%$ of sales.) The shortfall in the first year is statistically insignificant, while the second year shortfall is significant only at the $10 \%$ level. The EBITDA and EBITDA margin shortfalls are also smaller than those documented in Kaplan (1989a) for an earlier sample of management buyouts. Overall, therefore, there is weak evidence of optimistic EBITDA forecasts. But the closeness of the forecast and realized EBITDA margins suggests that the difference between forecast and actual EBITDA is related to the unanticipated recession instead of an ex ante bias.

\section{$6.2 \quad$ Leverage}

If cash flows forecasts are hardwired to repay debt, the hardwiring effect and the accuracy of the Compressed APV approaches should be more pronounced in more highly leveraged transactions. We test this implication of hardwiring by dividing the sample into firms that have above- and below-median post-transaction leverage (i.e., debt to transaction value). If hardwiring is causing our results, the Compressed APV techniques should be more accurate for the high debt sub-sample.

We do not find any significant difference in the performance of the Compressed APV approaches for the two sub-samples. Using the market-based APV approach, the estimated values are within $15 \%$ of transaction value for $56 \%$ of the low debt sub-sample and $65 \%$ of the high sub-sample. Also, the mean absolute error of the estimates in the lower debt sample is $17.1 \%$ of transaction value compared to $16.3 \%$ for the higher debt sample. Finally, the Compressed APV estimates (as multiples of EBITDA) for the lower debt sample explain more variation in transaction multiples than the estimates for the higher debt sample $-47 \%$ of the variation versus $29 \%$. 


\subsection{Initial Public Offerings}

Hardwiring implies that the APV approaches should not work as well in valuing companies that have little leverage. To explore the effectiveness of the Compressed APV approach in valuing firms with substantially less leverage than our HLT sample, we used the technique to estimate the value of firms in initial public offerings. The IPOs are also interesting because dealmakers in IPOs face incentives different from those in HLTs. In HLTs, cash flows may be upward biased to obtain financing or downward biased to obtain a fairness opinion. In the IPOs in our sample, there is an incentive to raise forecasts to get financing or get a higher price, but unlike HLTs - there is no incentive to lower forecasts. If hardwiring and associated incentives are causing spurious results in our HLT sample, the Compressed APV techniques should be higher and less accurate for the IPOs.

We obtained detailed cash flow forecasts for eight initial public offerings (IPOs) completed between October, 1991 and July, 1992. The IPOs all involved refinancing of existing debt because the eight issuers were companies that had previously completed highly leveraged transactions. We calculate the transaction value using the closing stock price on the day of the IPO. Based on this price, the median post-IPO leverage ratio of $52.6 \%$ is appreciably lower than the $87.9 \%$ for the sample HLTs.

Table 7 presents the results using the market-based APV approach with terminal value growth rates of $4 \%, 6 \%, 2 \%$, and $0 \%$. As with the HLT sample, we focus on the results using the $4 \%$ terminal value growth rate. Because expected inflation was arguably lower in 1991 and 1992 than in the earlier HLT period, however, we also discuss the results for the $2 \%$ growth rate.

Although the sample is small, the APV approach still performs fairly well. The median APV is $7.8 \%$ greater than firm value at a $4 \%$ terminal value growth rate, and $1.9 \%$ less than firm value at a $2 \%$ terminal value growth rate. The APV estimates are within $15 \%$ of firm value in $50.0 \%$ of the IPOs using $4 \%$ terminal value growth 
(and $37.5 \%$ of the IPOs using a $2 \%$ terminal value growth). Although this is less often than for the HLTs, such performance is as good as the comparable company and comparable industry performance for the HLTs. Finally, the APV estimates explain $37 \%$ of the variation in IPO value multiples, or approximately as much of the variation in HLT transaction value multiples that the DCF estimates explained.

\subsection{Contested and Uncontested HLTs}

Incentives to raise a cash flow forecast to justify a transaction ought to be higher when there are other bidders or some other form of outside pressure. In such situations, the failure to finance and complete the HLT both increases the likelihood that incumbent managers will lose their jobs (to the winning bidder) and ensures that dealmakers will lose their transaction fees. This suggests that in transactions that involve multiple bidders or hostile pressure, forecast cash flows ought to be higher relative to true "expected" cash flows. If this is the case, ex post performance relative to the forecasts ought to be lower. One might also argue that the APV estimates ought to be closer to the transaction values -- i.e., have smaller MAEs and MSEs - when there is hostile pressure. We find little support for these two hypotheses.

In our sample, 18 firms explicitly received competing bids and additional 6 firms experienced hostile pressure in the form of block share purchases by outside parties for a total of 24 firms with some form of outside pressure. There was no overt outside pressure for 27 transactions. The valuation errors are insignificantly different across the two sub-samples. Using a market-based APV approach (with $4 \%$ terminal value growth), the median APV estimate is $2.6 \%$ above the transaction value (mean is $0.2 \%$ ) when there is outside pressure and $1.6 \%$ below the transaction value (mean is $3.1 \%$ ) when there is not. The Compressed APV estimates are more accurate, but insignificantly so, when there is outside pressure. For example, the mean absolute error for the outside pressure sample is $14.4 \%$ compared to $18.7 \%$ for the non-hostile sample. Also, $67 \%$ of the outside pressure APV estimates are within $15 \%$ of transaction value compared to $56 \%$ of the APV estimates with no outside pressure. 
When we compare the ex post performance of the two sub-samples of HLTs to the cash flow forecasts, we find no significant differences in EBITDA or EBITDA margins. In the first and second post-transaction years, respectively, EBITDA levels are a median of $9.5 \%$ and $13.6 \%$ below those forecast for the outside pressure transactions and $2.8 \%$ and $20.5 \%$ below those forecast for the transactions with no outside pressure. Similarly, EBITDA margins are a median of $6.1 \%$ and $2.6 \%$ below those forecast for the outside pressure transactions and 2.0 and $4.6 \%$ below those forecast for the transactions with no outside pressure.

\subsection{Discussion}

The four sets of tests we perform all fail to support the predictions of hardwiring. In our view, there is no evidence to suggest that the reliability of the Compressed APV methods is spurious. However, without ex ante evidence that the cash flow forecasts are actually an estimate of expected cash flows, we cannot completely eliminate the possibility that dealmakers systematically and materially adjusted their cash flow forecasts. There may have been other pressures or incentives that we have not examined. We have, however, shown that the most obvious (at least to us) possible biases in the forecasts do not receive strong support from our data.

Furthermore, there are several reasons that adjustments to cash flows, especially larger ones, are costly. First, most of the dealmakers and investors in a particular HLT could expect to meet again in a future transaction. There were undoubtedly some reputational incentives not to present fictional forecasts. Second, in transactions that ultimately fail, creditors can sue insiders under fraudulent conveyance law if the original transaction rendered the company insolvent (solvency test) or the company had unreasonably small capital, i.e., insufficient forecast cash flow to meet debt payments (capital test). Both tests rely on the cash flow forecasts made at the time of the transaction. Courts and their examiners in fraudulent conveyance hearings have 
paid careful attention to whether the cash flow forecasts were "reasonable."1 The failure of the Interco recapitalization received such an unusual amount of attention precisely because the cash flow forecasts were considered to have been unreasonable.

Finally, academic and anecdotal evidence suggest that bankers and buyout specialists took the cash flow forecasts very seriously. Anders (1992) writes that the projections "took on a stature that was both awesome and terrifying to top executives. Unlike budgets that executives devised, the bank-book projections were ironclad." (Denis and Denis (1993) provide quantitative evidence that firms in recapitalizations were constrained by such budgets.) At a minimum, managers could expect that failure to meet those projections would bring increased scrutiny and pressure from banks and investors. To the extent that missed projections are followed by missed debt payments, equity investors could expect to lose their investment and managers could expect to lose their investment and their jobs.

\section{Summary}

This study provides evidence that discounted cash flow valuation methods provide reliable estimates of market value. Our median estimates of discounted cash flows for 51 HLTs are within $10 \%$ of the market values of the completed transactions and perform at least as well as valuation approaches using companies in similar industries and companies involved in similar transactions. We stress that our estimates rely on a number of ad hoc assumptions that readers (both academics and practitioners) should be able to improve on. We would expect such improvements to bring the DCF valuations even closer to the transaction values.

We use three CAPM-based approaches to estimate discount rates corresponding to firm-level, industry-level, and market-level measures of risk. All three methods perform well compared to those using comparable transactions and companies.

11 See Luehrman and Hirt (1991) and Baird (1991) for discussions of fraudulent conveyance law. 
Under what we consider the most realistic assumptions, the industry- and market-based approaches perform best.

Although the DCF approaches perform at least as well as the comparablebased approaches, we find that the comparable-based estimates add explanatory power to the DCF-based estimates. Accordingly, we would recommend using information from both types of approaches in practical valuation settings where comparable values are available.

In the second part of this paper, we use the forecast cash flows and transaction values to calculate implied discount rates and risk premiums. The median implied market equity risk premium, the amount by which the return on the equity market exceeds the long-term Treasury bond yield, equals $7.55 \%$. This accords well with the historical risk premium by which returns on the S\&P 500 have exceeded Treasury bond returns. The relations between the implied risk premiums and both firm and industry betas are positive and marginally significant. In contrast, there are no apparent relations between the implied risk premiums and either transaction value, i.e., firm size, or bookto-market ratios. For this sample, therefore, the results favor CAPM-based approaches to discount rates over those based on size or book-to-market ratios. 
Anders, George, 1992, Merchants of Debt. New York: Basic Books.

Baird, Douglas, 1991, Fraudulent conveyances, agency costs, and leveraged buyouts, 20 Journal of Legal Studies 1.

Black, Fischer, 1986, Noise, Journal of Finance 41, 529-544.

Blanchard, Olivier, 1993, Movements in the equity premium, Brookings Papers on Economic Activity 2, 75-138.

Blume, Marshall, 1975, Betas and their regression tendencies, Journal of Finance 30, 785-795.

Brealey, Richard and Stewart Myers, 1991, Principles of Corporate Finance. New York: McGraw-Hill, 4th Edition.

Burrough, Bryan, and John Helyar, 1990, Barbarians at the Gate. New York: Harper and Row.

Cornell, Bradford and Kevin Green, 1991, The investment performance of low grade bond funds, Journal of Finance 46, 29-48.

DeAngelo, Linda, 1990, Equity valuation and corporate control, The Accounting Review 65, 93-112.

Denis, David and Diane Denis, 1993, Managerial discretion, organizational structure, and corporate performance: A study of leveraged recapitalizations, Journal of Accounting and Economics 16, 209-236.

Dimson, Elroy, 1979, Risk measurement when shares are subject to infrequent trading, Journal of Financial Economics 7, 197-226.

Fama, Eugene, and Kenneth French, 1992, The cross-section of expected stock returns, Journal of Finance 47, 427-466.

Ibbotson Associates, 1991, Stocks, Bonds, Bills, and Inflation 1991 Yearbook, Chicago: Ibbotson Associates, Inc. 
Kaplan, Steven, 1989a, The effects of management buyouts on operations and value, Journal of Financial Economics 24, 217-254.

Kaplan, Steven, 1989b, Campeau's acquisition of Federated: Value destroyed or value added? Journal of Financial Economics 25, 191-212.

Kaplan, Steven and Jeremy Stein, 1990, How risky is the debt in highly leveraged transactions? Journal of Financial Economics 27, 215-246.

Kaplan, Steven and Jeremy Stein, 1993, The evolution of buyout pricing and financial structure in the 1980s, Quarterly Journal of Economics, Volume CVIII, Issue 2, 313-358.

Kim, Moonchul, and Jay Ritter, 1994, Earnings, book value, and comparable firms in the valuation of IPOs, Working paper, University of Illinois, Champagne, IL.

Klemkosky, Robert and John Martin, 1975, The adjustment of beta forecasts, Journal of Finance 30, 1123-1128.

Luehrman, Timothy and Lance Hirt, 1991, Highly levered transactions and fraudulent conveyance law, Working paper, Harvard Business School, Boston, MA.

Modigliani, Franco and Merton Miller, 1963, Corporate income taxes and the cost of capital, American Economic Review, 433-443.

Ruback, Richard, 1989, RJR Nabisco, Harvard Business School Teaching Note, 5-289-057.

Stevens, Ross, 1993, New methods in testing asset pricing models, Working paper, University of Chicago, Chicago, IL.

Vasicek, Oldrich, 1973, A note on using cross-sectional information in Bayesian estimation of security betas, Journal of Finance 28, 12331239. 
Table I

Highly leveraged transactions with usable projections by year of transaction, by type of transaction, and by whether the projections reflect the transaction for 136 management buyouts and highly leveraged transactions completed between 1980 and 1989.

\begin{tabular}{|c|c|c|c|c|c|c|}
\hline \multirow[t]{2}{*}{ Year } & \multicolumn{2}{|c|}{ All Transactions } & \multicolumn{2}{|c|}{ MBOs } & \multicolumn{2}{|c|}{ Recapitalizations } \\
\hline & Total & $\begin{array}{r}\text { Reflect } \\
\text { Transaction }\end{array}$ & Total & $\begin{array}{r}\text { Reflect } \\
\mathrm{MBO}\end{array}$ & Total & $\begin{array}{r}\text { Reflect } \\
\text { Recap }\end{array}$ \\
\hline 1983 & 1 & 0 & 1 & $\mathbf{0}$ & 0 & 0 \\
\hline 1984 & 2 & 0 & 2 & 0 & 0 & 0 \\
\hline 1985 & 3 & 3 & 2 & 2 & 1 & 1 \\
\hline 1986 & 8 & 8 & 4 & 4 & 4 & 4 \\
\hline 1987 & 6 & 3 & 5 & 2 & 1 & 1 \\
\hline 1988 & 24 & 14 & 22 & 12 & 2 & 2 \\
\hline 1989 & 7 & 5 & 7 & 5 & 0 & 0 \\
\hline Total & 51 & 33 & 43 & 25 & 8 & 8 \\
\hline
\end{tabular}


Table 2

Comparison of different valuation methods

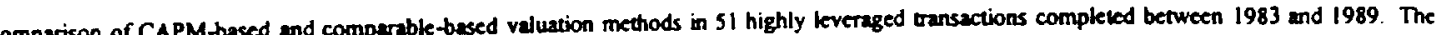
first four reve valuation errors equal the natural

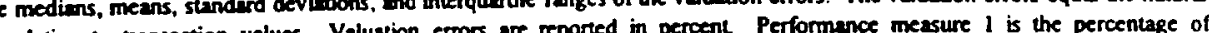
log of estimated values relative to transaction values. Valuation errors are reported in percent. Performance measure 1 is the percentage of transections in which absolute value of the valuation errors is less than or equal to $15 \%$. Pertormance measure 2 is the mean absolute errot of the valuation errors (in percent). Performance measure 3 is the mean squared error of valuation errors (in pereeni). Periormance meas $4 A$ and $4 B$ cqual the percentage of transactions in which $(4 \mathrm{~A})$ the estimued value exceeds the transaction value and the HLT subsequently defauls on its debr payments (accepe bad deals); and (AB) the estimated value is less than the transaction value and the HLT does payments (aces bestimated present values of projected capitai cash flows. Terminal values are grown at $4 \%$. Discount good deals). CAPM-based values are the estimated present values of projected capina cash hows. Terition the relevant asset beta. The rist. raves equal the longterm Treasury bond yicld a the time of the projections plus the equity risk prenium tirnes the relevant aser beta. The ist premium is the arithmetic average premium of the S\&P 500 return over the longterm Tressury bond retum from 1926 until the yesr betore the tas in

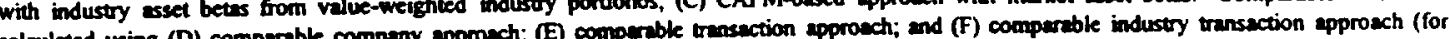

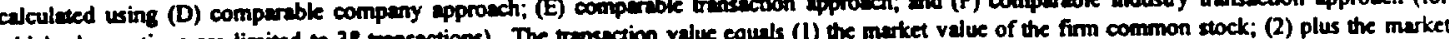

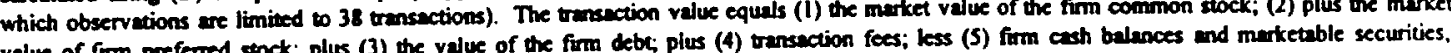

value of firm preferred stock; plus (3) the value of the firm debc; pies (4) transiction fees; less (S) firm cass balances and make

\begin{tabular}{|c|c|c|c|c|c|c|}
\hline & \multicolumn{3}{|c|}{ CAPM-Besed Valuation Methods } & \multicolumn{3}{|c|}{ Comperable Valuntion Methods } \\
\hline & $\begin{array}{l}\text { (A) } \\
\text { Firm Beta }\end{array}$ & $\begin{array}{l}\text { (B) } \\
\text { Industry } \\
\text { Beta }\end{array}$ & $\begin{array}{l}\text { (C) } \\
\text { Mutret } \\
\text { Bet }\end{array}$ & $\begin{array}{l}\text { (D) } \\
\text { Comparable } \\
\text { Compeny }\end{array}$ & $\begin{array}{l}\text { (E) } \\
\text { Comparable } \\
\text { Transection }\end{array}$ & $\begin{array}{l}\text { (F) } \\
\text { Comparable } \\
\text { Industry Transaction } \\
(\mathrm{N}=38)\end{array}$ \\
\hline \multicolumn{7}{|c|}{ I. Summary Statistics for Valuation Errors: } \\
\hline 1. Median & $6.0 \%$ & $3.2 \%$ & $1.0 \%$ & $-18.1 \%$ & $5.9 \%$ & $-0.1 \%$ \\
\hline 2. Mean & $6.3 \%$ & $43 \%$ & $1.5 \%$ & $-16.6 \%$ & $0.3 \%$ & $.0 .7 \%$ \\
\hline 3. Stendard Deviation & $27.2 \%$ & $23.3 \%$ & $22.5 \%$ & $25.4 \%$ & $22.3 \%$ & $28.7 \%$ \\
\hline 4. Interquartile Range & $32.7 \%$ & $19.9 \%$ & $26.4 \%$ & $41.9 \%$ & $32.2 \%$ & $23.7 \%$ \\
\hline 5. Asset Beta (median) & 0.85 & 0.88 & 0.93 & & & \\
\hline \multicolumn{7}{|c|}{ 11. Performance Messures for Valuneion Errors: } \\
\hline 1. Pct within $15 \%$ & $49.0 \%$ & $64.7 \%$ & $60.8 \%$ & $37.3 \%$ & $47.1 \%$ & $57.9 \%$ \\
\hline 2. Mean Absolute Error & $20.0 \%$ & $16.5 \%$ & $16.7 \%$ & $24.7 \%$ & $18.1 \%$ & $20.5 \%$ \\
\hline 3. Mean Squared Error & $7.6 \%$ & $5.5 \%$ & $5.0 \%$ & $9.1 \%$ & $4.9 \%$ & $8.0 \%$ \\
\hline 4A. \% Accept bad deals & $21.6 \%$ & $23.5 \%$ & $25.5 \%$ & $9.8 \%$ & $21.6 \%$ & $13.2 \%$ \\
\hline 48. \% Reject good deals & $23.5 \%$ & $29.4 \%$ & $39.2 \%$ & $47.1 \%$ & $31.4 \%$ & $28.9 \%$ \\
\hline
\end{tabular}




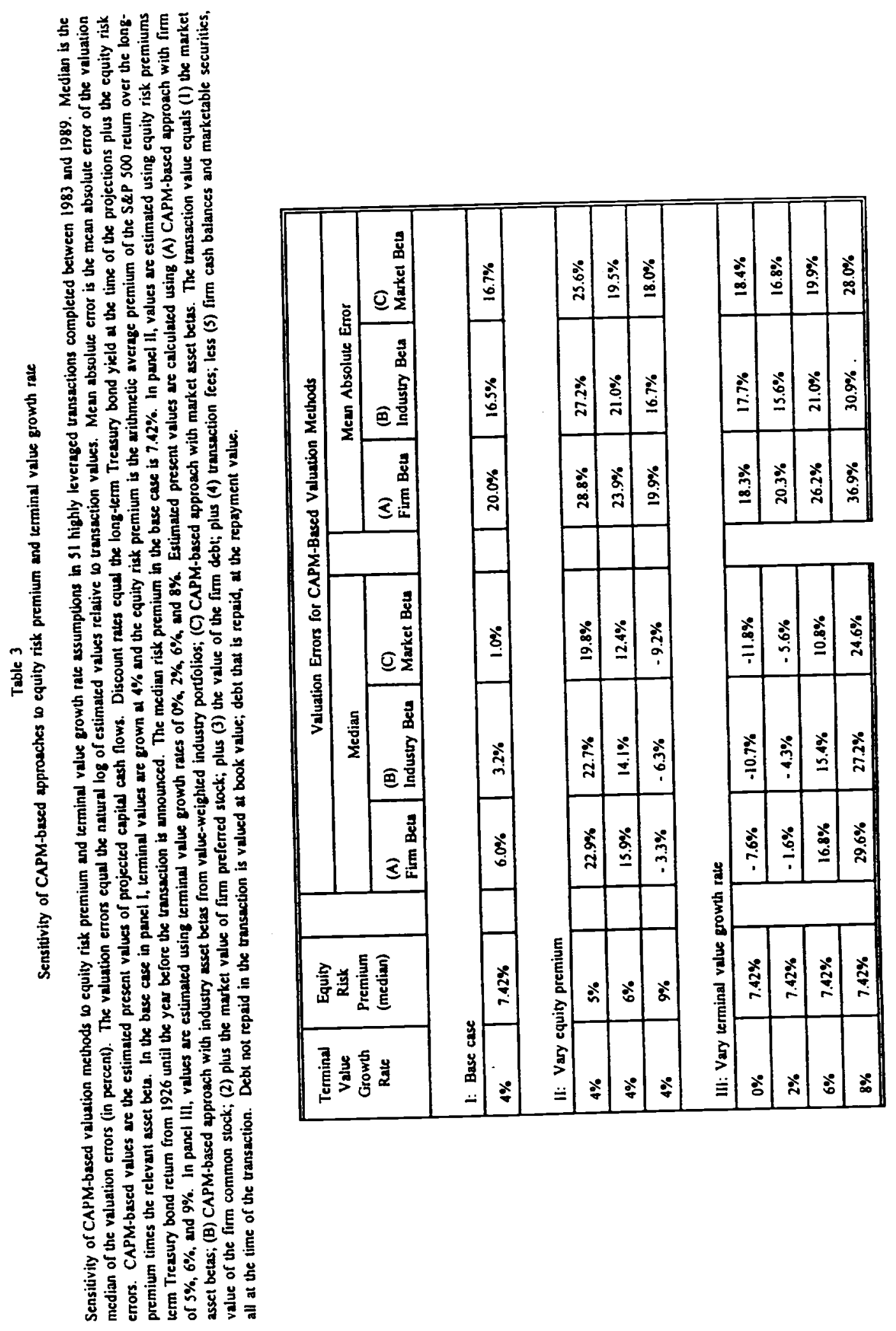


Table 4

Cross-sectional relation of estimaled values to transaction values

Regressions of Estimated (B) CAPM-based approsch with industry asset betss from net present values are calculated using (A) CAPM-based approach with frm asset bes; (B) CAPM-based approsch wisp ind comparable company approsch; ind (E) comparable value-weighted industry portolios; (C) CAPM-based approsch with market asset betas; (D) conparable company approse halue equals (1) the market value of the trensection spproech. All CAPM-besed epproeches use a terminal value growth race of 4\%. Transaction value equs (4) transection fees; kess (5) firm firm common stock; (2) plus the market value of furm preferred slock; plus (3) the value of the frm debr; plus (1) trastiod at book value; debe that is cash balances and marketable securities, all at the time of the ton repaid, at the repayment value. Standard errors are in brackets.

Dependent variable is trensaction value or transaction value as a multiple of prior yesr EBITDA

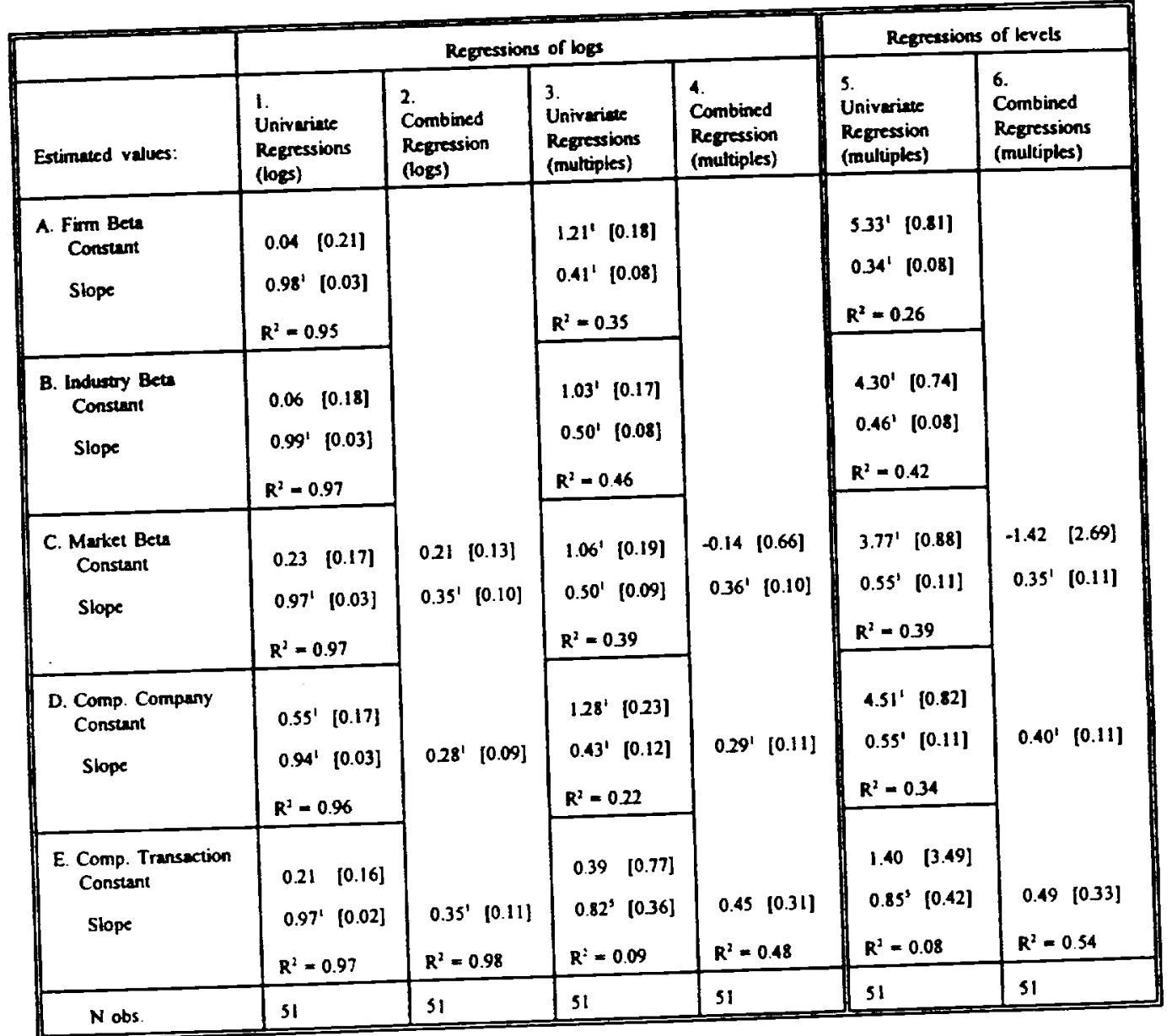

Significantly different from zero at the $1 \%$ level '; at the $5 \%$ levet '; and at the $10 \%$ level 10 
Table 5

Implied discount rates, risk premiums, and market equity risk premiums

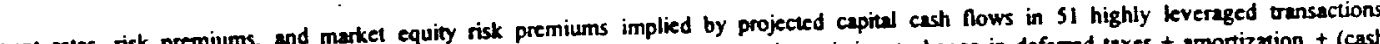

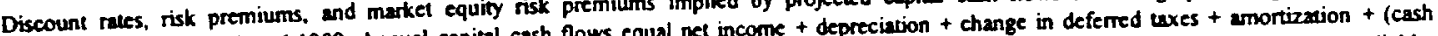
completed between 1983 and 1989. Annual capital cash flows equa net income tepreciabon t change in deferred ches then net income is not available. and non-cash) interest - capital expenditures - increase in net working capital + anter-lax proceds of asset sales. When net incoment interest - cepital apd

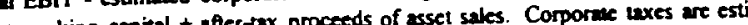
expenditures - increase in net working capital a dectax proced thansaction value equals (1) the market between EBIT and interest paymenis. Terminal growth rale ssumed

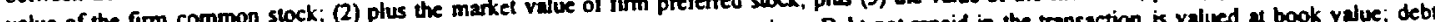

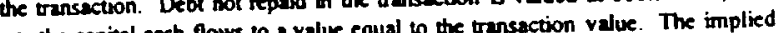

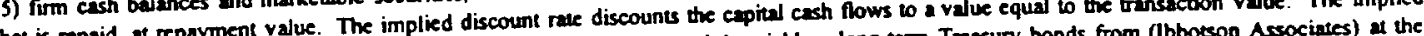
that is repaid, at repay the difference between the implied discount rate and the yield on long-term Treasury bonds from (bbotson The implied market equity risk premium uses the value weighted ceppital structure for time of the projections. The implied market equiry isk prent to transform the implied risk premium into the risk premium for an investment with the SaP 500 in

a beta of 1 .

\section{A: Implied Discoum Rate}

\begin{tabular}{|l|l|l|l|l|l|l|l|}
\hline $\begin{array}{l}\text { Terminal Value } \\
\text { Growth Rate }\end{array}$ & Median & Mean & $\begin{array}{l}\text { Sid. } \\
\text { Dev. }\end{array}$ & $\begin{array}{l}\text { Inverquar } \\
\text { Range }\end{array}$ & Min. & Max. & N \\
\hline $4 \%$ & 15.77 & 16.28 & 2.69 & 3.06 & 10.37 & 24.16 & 51 \\
\hline $6 \%$ & 16.77 & 17.32 & 2.64 & 2.80 & 11.55 & 25.39 & 51 \\
\hline $2 \%$ & 14.85 & 15.29 & 2.75 & 3.24 & 9.29 & 23.16 & 51 \\
\hline $0 \%$ & 13.79 & 14.36 & 2.83 & 3.50 & 829 & 22.46 & 51 \\
\hline
\end{tabular}

B: Implied Risk Premium

\begin{tabular}{|c|c|c|c|c|c|c|c|}
\hline $\begin{array}{l}\text { Terminal Value } \\
\text { Gronth Rate }\end{array}$ & Median & Mean & $\begin{array}{l}\text { Sed. } \\
\text { Der. }\end{array}$ & $\begin{array}{l}\text { Interquert } \\
\text { Runge }\end{array}$ & Min. & Max. & $\mathbf{N}$ \\
\hline $4 \%$ & 7.07 & 7.14 & 2.87 & 2.76 & 0.90 & 15.85 & 51 \\
\hline $6 \%$ & 8.16 & 8.18 & 2.84 & 2.42 & 2.08 & 16.98 & 51 \\
\hline $2 \%$ & 5.82 & 6.16 & 2.93 & 2.93 & -0.00 & 14.75 & 51 \\
\hline $0 \%$ & 5.00 & 5.22 & 2.99 & 2.76 & -1.26 & 14.02 & 51 \\
\hline
\end{tabular}

C. Implied Market Equity Risk Premium

\begin{tabular}{|c|c|c|c|c|c|c|c|}
\hline $\begin{array}{l}\text { Terminal Value } \\
\text { Growh Rate }\end{array}$ & Median & Mesn & $\begin{array}{l}\text { Sid. } \\
\text { Dev. }\end{array}$ & $\begin{array}{l}\text { Interquart } \\
\text { Runge }\end{array}$ & Min. & Max. & $\mathbf{N}$ \\
\hline $4 \%$ & 7.55 & 7.74 & 3.19 & 2.95 & 0.97 & 17.98 & 51 \\
\hline $6 \%$ & 8.81 & 8.87 & 3.16 & 2.64 & 2.24 & 19.25 & 51 \\
\hline $2 \%$ & 6.82 & 6.67 & 3.24 & 3.20 & -0.20 & 16.72 & 51 \\
\hline $0 \%$ & 5.46 & 5.66 & 3.30 & 2.97 & -1.40 & 15.53 & 51 \\
\hline
\end{tabular}

